\title{
URBANISASI, INDUSTRIALISASI, PENDAPATAN, DAN PENDIDIKAN DI INDONESIA
}

\section{Oleh : Al Muizzuddin Fazaalloh ${ }^{1}$}

\begin{abstract}
Abstrak
Paper ini meneliti tentang dampak industrialiasi, tingkat pendapatan, dan tingkat pendidikan terhadap urbanisasi di Indonesia selama periode 1960-2016. Penelitian ini menggunakan metode kuantitatif dengan pendekatan regresi OLS. Hasil penelitian ini menunjukkan bahwa industrialisasi memiliki pengaruh signifikan dan negatif terhadap urbanisasi, tingkat pendapatan juga memiliki pengaruh yang signifikan dan negatif, kemudian tingkat pendidikan memiliki kontribusi yang signifikan dan positif terhadap urbanisasi di Indonesia.
\end{abstract}

Kata kunci: urbanisasi, perekonomian, pendidikan, industrialisasi, pertanian

\section{Abstract}

This paper analyzed the influence of industrialization, income, and education on urbanization in Indonesia over period 1960-2016. Quantitative method is applied with model OLS regression to exam the relation between those variables. The results show that both industrialization and income have significant and negative impact on urbanization. Moreover, education have significant and positive impact on urbanization in Indonesia.

Keywords: urbanization, economy, education, industrialization, agricultural sector

\footnotetext{
${ }^{1}$ Staff Pengajar Jurusan Ekonomi Pembangunan, Fakultas Ekonomi dan Bisnis, Universitas Brawijaya, Malang/ almuiz.wang@ub.ac.id
} 


\section{Latar Belakang}

Urbanisasi merupakan tren dari kemajuan ekonomi di negara berkembang yang ada di dunia saat ini. Banyak negara berkembang yang mengalami hal tersebut dan menjadi sebuah tantangan di dalam pengembangan perekonomian. Hal ini juga dialami oleh Indonesia sebagai negara berkembang saat ini, yang mana pendapatan per kapita Indonesia hingga tahun 2016 sudah mencapai US\$ 3570,3 (World Development Indicator, 2017).

Perkembangan urbanisasi di Indonesia dalam 40 tahun terakhir (1970-2010) cukup signifikan. Dalam laporan Bank Dunia (2012) disebutkan bahwa pada tahun 1971 penduduk kota memiliki presentase sebesar 17,2\%. Nilai ini terus meningkat hingga di tahun 2010 telah mencapai 49,8\%. Artinya, pertumbuhan urbanisasi di Indonesia sejak puluhan tahun yang lalu telah meningkat secara drastis. Lebih lanjut, bahkan Bank Dunia memproyeksi bahwa penduduk kota di tahun 2025 di Indonesia akan dapat mencapai $67,5 \%$.

Peningkatan urbanisasi yang fantastis ini perlu mendapat perhatikan dari para pakar ekonom maupun sosial. Hal tersebut penting mengingat dengan banyaknya penduduk kota maka suatu kota harus mempersiapkan diri dalam menampung jumlah penduduk yang lebih besar. Dalam konteks ini, kota harus mempersiapkan infrastruktur yang lebih bagus, membuka lapangan pekerjaan yang lebih luas, dan meningkatkan investasi untuk pelayanan publik secara lebih baik.

Di luar itu, penting pula untuk mengetahui faktor-faktor yang mendorong masyarakat melakukan urbanisasi. Hal ini perlu dilakukan agar pengambil kebijakan dapat mengontrol arus urbanisasi dan mempersiapkan secara lebih baik dalam upaya menyambut derasnya arus urbanisasi. Berbagai penelitian telah dilakukan dalam melihat faktor apa saja yang mendorong adanya urbanisasi di perkotaaan.

Moomaw dan Shatter (1996) menemukan bukti yakni urbanisasi bergerak dengan adanya peningkatan pendapatan perkapita, industrialisasi, dan kegiatan ekspor. Selanjutnya, Brückner (2012) mendapatkan hasil bahwa penurunan nilai tambah pada sektor pertanian dapat membuat peningkatan arus urbanisasi di Afrika. Hofmann dan Wan (2013) menyampaikan hasil bahwa pertumbuhan ekonomi akan mendorong urbanisasi secara positif. Disamping itu, mereka juga menjelaskan bahwa industrialisasi dan pendidikan memiliki peran positif di dalam mendorong urbanisasi. 
Pada penelitian terbaru, Glaeser (2014) menemukan hasil bahwa urbanisasi dapat dipengaruhi oleh kurang majunya sektor pertanian (untuk negara dengan perekonomian terbuka). Flückiger dan Ludwig (2017) menemukan bahwa tingkat fertilitas dan investasi untuk pendidikan anak-anak merupakan faktor yang berpengaruh signifikan terhadap arus urbanisasi di negara-negara Sub Sahara Afrika.

Melihat penelitian terdahulu yang memberikan hasil yang cukup beragam maka penelitian ini bertujuan untuk menganalisis bagaimana pengaruh industrialisasi, pendapatan, dan pendidikan di Indonesia. Penelitian ini berbeda dengan penelitian sebelumnya pada dua hal berikut. Pertama, penelitian ini menggunakan data yang lebih lama (1960-2016). Kedua, penelitian ini menggunakan data di Indonesia, dimana sangat jarang peneliti sebelumnya menggunakan kasus di Indonesia, yang mana Indonesia sebagai negara berkembang tentunya akan menarik untuk diteliti mengingat fenomena urbanisasi yang ada sekarang trennya terus meningkat.

Paper ini disusun sebagai berikut. Sesi kedua akan menjelaskan penelitian terdahulu, kemudian akan dilanjutkan dengan metode penelitian. Sesi keempat akan menjelaskan hasil dan diskusi. Terakhir, kesimpulan dan rekomendasi kebijakan akan disajikan.

\section{Penelitian Terdahulu}

Hingga dewasa ini, cukup banyak penelitian yang berkaitan dengan urbanisasi sudah dilakukan oleh para ahli ekonom maupun sosial. Penelitian yang terkenal dan paling lama tercatat dilakukan oleh Pandey (1977). Dia meneliti tentang bagaimana dampak variabel-variabel sosial dan ekonomi terhadap tingkat urbanisasi di negara India, sebagai negara berkembang pada saat itu. Hasilnya adalah ditemukannya variabel rasio antara jumlah penduduk terhadap jumlah lahan berdampak negatif terhadap tingkat urbanisasi. Hal ini dapat terjadi karena ketika penduduk di desa atau di sektor pertanian cukup banyak dan sektor pertanian sudah cukup maju, maka upah petani akan mahal. Kemudian industrialisasi menunjukkan hubungan yang positif terhadap urbanisasi. Hal ini mengimplikasikan bahwa urbanisasi merespon lebih besar terhadap industrialisasi dibandingkan perubahan tingkat urbanisasinya sendiri. Berikutnya adalah pengaruh dari hasil panen di sektor pertanian, dimana hasilnya menunjukkan pengaruh yang negatif. Hal ini berarti bahwa semakin tinggi hasil panen maka akan mengurangi tingkat urbanisasi. Pandey 
berargumen bahwa untuk menekan tingkat urbanisasi maka kebijakan yang tepat adalah dengan mendorong perkembangan sektor pertanian secara lebih cepat.

Hofmann dan Wan (2013) menganalisis pengaruh pertumbuhan ekonomi, pendidikan, dan industrialisasi terhadap urbanisasi. Hasilnya, pertumbuhan ekonomi berpengaruh terhadap urbanisasi secara signifikan, kemudian efek dari pendidikan adalah positif terhadap urbanisasi. Terakhir, industrialisasi juga berdampak positif terhadap urbanisasi. He dan Sim (2015) juga menemukan bahwa pertumbuhan ekonomi dapat mempengaruhi urbanisasi secara positif untuk kasus di China. Dalam penelitian mereka, data yang digunakan adalah data pada level propinsi di China sejak 1985-2008.

\section{Model dan Data Penelitian}

Untuk menganalisis dampak dari industrialisasi, pendapatan, dan pendidikan terhadap urbanisasi di Indonesia, penelitian ini menggunakan pendekatan kuantitaif dengan model regresi OLS. Data yang digunakan dalam penelitian ini adalah selama periode 1960-2016. Sumber data dalam penelitian ini berasal dari publikasi data statistik secara online dari World Development Indicators yang diterbitkan oleh Bank Dunia. Adapun model regresi dari penelitian ini adalah sebagai berikut:

$$
\mathrm{Y}=\alpha+\beta 1 \mathrm{X}_{1}+\beta 2 \mathrm{X}_{2}+\beta 3 \mathrm{X}_{3}+\mathrm{e}
$$

dimana, Y sebagai yariabel urbanisasi diproksikan dengan nilai rata-rata tahunan tingkat perubahan persentase penduduk kota. X1 adalah variabel industrialisasi yang diproksikan dengan nilai persentase dari rasio antara jumlah lahan pertanian terhadap total lahan. Kemudian X2 yakni variabel pendapatan yang diproksikan dengan nilai PDB perkapita dalam satuan US dollar. Terakhir, X3 adalah pendidikan yang diproksikan dengan nilai rata-rata lama sekolah untuk penduduk yang berusia 15 tahun ke atas dalam satuan tahun. 


\section{Hasil Penelitian}

Hasil regresi dari dampak variabel industrialisasi, pendapatan, dan pendidikan terhadap urbanisasi disajikan pada tabel 1 berikut:

\section{Tabel 1. Hasil Analisis Pengaruh Industrialisasi, Pendapatan, Dan Pendidikan}

Terhadap Urbanisasi di Indonesia (1960-2016).

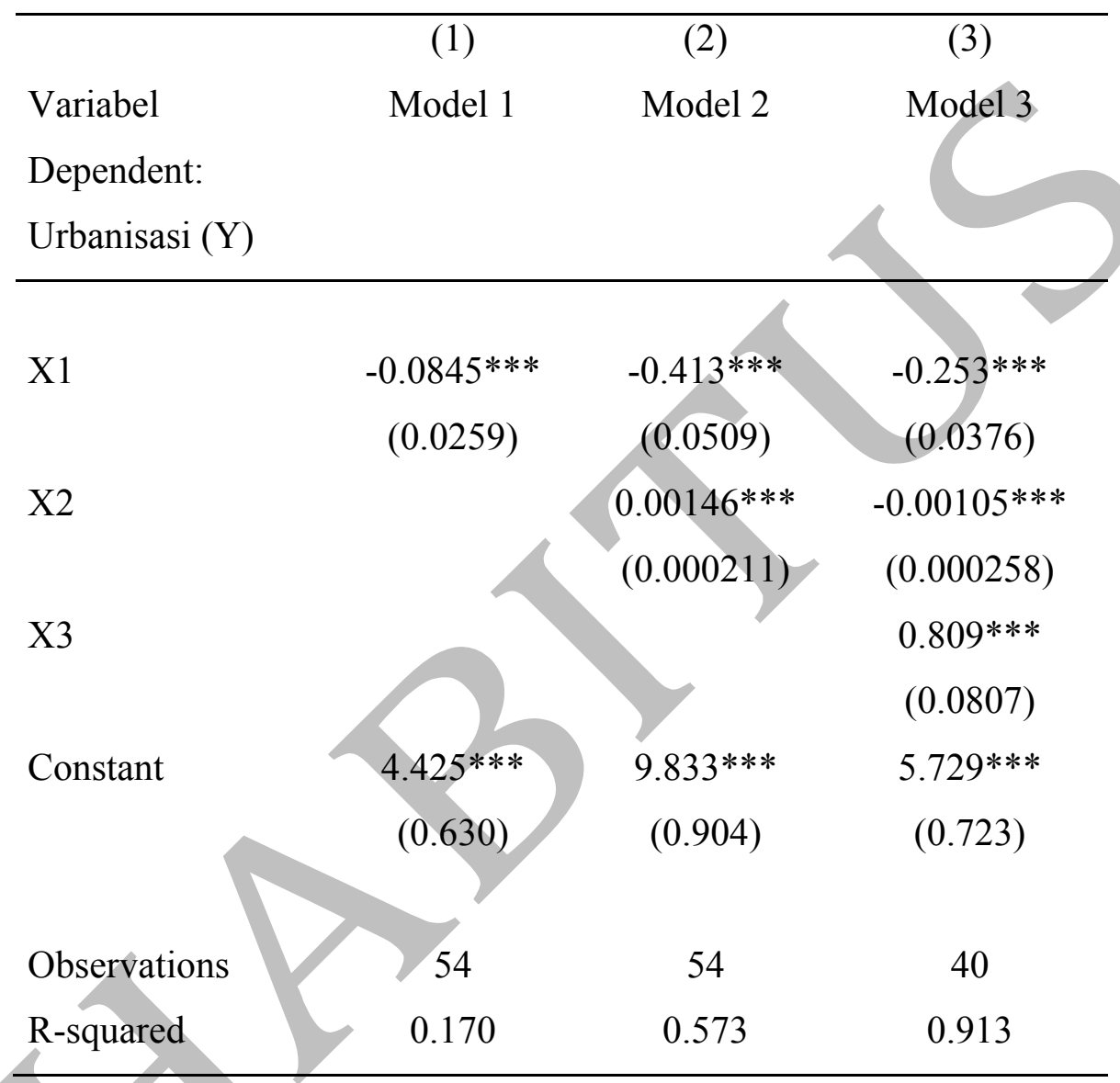

Catatan: Standard errors di dalam kurung

$* * * \mathrm{p}<0.01, * * \mathrm{p}<0.05, * \mathrm{p}<0.1$

Pada model 1 dapat dijelaskan bahwa pengaruh variabel industrialisasi terhadap urbanisasi adalah signfikan dengan koefisien negatif. Ketika tingkat industrialisasi meningkat $1 \%$ maka akan mengurangi tingkat urbanisasi sebesar $0,08 \%$.

Pada model 2 ditambahkan variabel pendapatan. Pengaruh dari variabel industrialisasi terhadap urbanisasi tetap signifikan dan negatif koefisiennya. Namun nilai koefisiennya lebih besar dibandingkan pada model 1. Pada variabel pendapatan, 
pengaruhnya terhadap urbanisasi adalah signifikan dan positif. Artinya, setiap peningkatan sebesar US\$ 1.000 pada pendapatan perkapita maka akan meningkatkan urbanisasi $1,46 \%$.

Pada model 3 ditambahkan variabel pendidikan. Hasilnya, pengaruh dari variabel industrialisasi signifikan dan negatif terhadap urbanisasi. Sedangkan pengaruh dari pendapatan berubah menjadi signifikan dan negatif. Sedangkan pengaruh dari variabel pendidikan adalah signifikan dan positif terhadap urbanisasi. Artinya, setiap peningkatan tingkat pendidikan sebesar 1\% maka akan berdampak pada peningkatan urbanisasi sebesar $0,8 \%$.

\section{Dikusi}

Pengaruh negatif dari variabel industrialisasi terhadap urbanisasi ini memiliki makna bahwa urbanisasi tidak disebabkan oleh industrialisasi. Lebih lanjut, Pandey (1977) memberikan pendapat bahwa urbanisasi ini tidak berjalan sesuai dengan perkembangan sektor non-pertanian. Argumen ini mendukung tesis tentang overubanization, dimana urbanisasi terjadi bukan karena perkembangan sektor industri namun dorongan dari lahan pertanian yang sudah tidak lagi mampu menjadi tumpuan hidup masyarakat di perdesaan.

Peningkatan pendapatan dari hasi regresi tersebut menjelaskan bahwa urbanisasi akan meningkat. Hal ini mengimplikasikan bahwa tingkat pendapatan merupakan faktor yang penting untuk menarik masyarakat perdesaan untuk bermigrasi ke kota. Lebih lanjut, pendapatan yang tinggi dapat juga dimaknai dengan upah yang tinggi di perkotaan, maka akan membuat masyarakat ingin mendapatkan pekerjaan disektor industri atau di perkotaan. Sehingga arus urbanisasi akan semakin meningkat. Kondisi sebaliknya, pengaruh negatif dari pendapatan maka mengimplikasikan bahwa sektor pertanian di suatu negara tersebut telah berkembang secara baik sehingga peningkatan pendapatan tidak akan menarik masyarakat desa pindah ke kota. Selain itu, hal ini dapat dimungkinkan terjadi karena pembangunan ekonomi di perdesaan telah berjalan secara baik seperti pelayanan publik di bidang kesehatan maupun pendidikan dan infrastruktur telah dapat dipenuhi oleh pemerintah.

Pendidikan berpengaruh positif terhadap urbanisasi. Hal ini memiliki implikasi bahwa peran pendidikan di dalam urbanisasi adalah penting. Dengan pendidikan yang tinggi maka masyarakat memiliki kesempatan untuk mendapatkan 
pekerjaan yang lebih baik di perkotaan. Maka semakin tinggi pendidikan akan mendorong masyarakat untuk dapat mencari pekerjaan yang lebih layak di perkotaan.

\section{Kesimpulan dan Rekomendasi}

Tren urbanisasi di Indonesia saat ini adalah meningkat. Peningkatan ini tentu disebabkan oleh berbagai faktor ekonomi dan sosial. Untuk itu penting dilakukan penelitian terkait faktor-faktor yang mempengaruhi urbanisasi di Indonesia. Penelitian ini memiliki tujuan yakni mengestimasi pengaruh dari industrialisasi, pendapatan, dan pendidikan terhadap urbanisasi di Indonesia. Dengan menggunakan data yang lebih lama (1960-2016), penelitian ini mencoba mengungkapkan hubungan variabelvariabel tersebut dengan pendekatan kuantitatif yakni dengan model regresi OLS. Hasil penelitian ini adalah pengaruh industrialisasi terhadap urbanisasi adalah negatif. Kemudian pengaruh dari pendapatan terhadap urbanisasi menghasil dua hasil yakni positif dan negatif. Terakhir, pengaruh pendidikan adalah positif.

Untuk mengendalikan arus urbanisasi, maka pemerintah perlu memahami bagaimana kondisi industrialisasi, tingkat pendapatan, dan tingkat pendidikan di Indonesia. Berikut beberapa rekomendasi kebijakan yang dapat dilakukan oleh pemerinah. Pertama, mengingat pembangunan sektor pertanian menjadi hal penting untuk mencegah terjadinya overurbanization di Indonesia maka pemeritah perlu meningkatkan kualitas hasil panen dan daya beli petani. Kedua, pemerintah perlu membangun kawasan desa dengan meningkatkan prasarana dan sarana infrastrtuktur dan pelayanan publik di bidang kesehatan dan pendidikan, hal ini akan dapat meningkatkan pendapatan perkapita dari masyarat sehingga urbanisasi yang tinggi dapat dicegah. Ketiga, pemerintah perlu memperhatikan pendidikan masyarakat dengan cara mendorong masyarakat untuk dapat studi hingga perguruan tinggi agar kesempatan mendapatkan pekerjaan yang layak dapat tercapai yang pada akhirnya akan mendorong arah urbanisasi yang tidak berlebihan. 


\section{Daftar Pustaka}

Bank Dunia (2012). Indonesia: The Rise Of Metropolitan Regions: Towards Inclusive And Sustainable Regional Development. Bank Dunia.

Brückner, M. (2012). Economic growth, size of the agricultural sector, and urbanization in Africa. Journal of Urban Economics, 71(1), 26-36. https://doi.org/10.1016/j.jue.2011.08.004

Flückiger, M., \& Ludwig, M. (2017). Urbanization, fertility and child education in Sub-Saharan Africa. Economics Letters, 157, 97-102. https://doi.org/10.1016/j.econlet.2017.05.024

Glaeser, E. L. (2014). A world of cities: The causes and consequences of urbanization in poorer countries. Journal of the European Economic Association, 12(5), 1154-1199. https://doi.org/10.1111/jeea.12100

He, X., \& Sim, N. C. S. (2015). Does economic growth affect urbanization? New evidence from China and the Chinese National Congress. Journal of Asian Economics, 36, 62-71. https://doi.org/10.1016/j.asieco.2014.12.003

Hofmann, A., \& Wan, G. (2013). Determinants of urbanization. ADB Economics Working Paper Series, 355(355), 1-31.

Moomaw, R. L., \& Shatter, a M. (1996). Urbanization and economic development: a bias toward large cities? Journal of Urban Economics, 40, 13-37. https://doi.org/10.1006/juec.1996.0021

Pandey, S. M. (1977). Nature and determinants of urbanization in a developing economy: The case of India. Economic Development and Cultural Change, 25(2), 265-278.

Web:

World Development Indicators. (2017).

http://databank.worldbank.org/data/reports.aspx?source=world-developmentindicators diakses pada 24 Agustus 2017 